\title{
Energy consumption and thermal properties of drying banana (musa ssp) under varied relative humidity
}

\author{
F. SARPONG*, M. T. RASHID, J. OWUSU-KWARTENG \& C. ZHOU \\ (F.S.: Council for Scientific and Industrial Research (CSIR)-Oil Palm Research Institute, P. \\ O. Box 74, Kade, Ghana; M.T.R \& C.Z.: School of Food and Biological Engineering, Jiangsu \\ University, No. 301 Xuefu Road, Zhenjiang, 212013, China; J.O-K.: Department of Food \\ Science and Technology, University of Energy and Natural Resources, Sunyani, Ghana) \\ *Corresponding author's e-mail: fsarpong@csir.org.gh
}

\begin{abstract}
The drying of banana slices was investigated under different relative humidity $(\mathrm{RH})$ in a convective hot-air dryer. The experiments were conducted using $10,20,30$ and $40 \% \mathrm{RH}, 75^{\circ} \mathrm{C}$ and $2.0 \mathrm{~m} / \mathrm{s}$ air velocity drying conditions. Drying kinetics, energy consumption and thermal properties were investigated. Eight mathematical models describing thin layer drying were employed and results were compared to their goodness of fit in terms of coefficient of correlation $\left(\mathrm{R}^{2}\right)$, the root mean square error (RMSE) and the reduced chi square $\left(\chi^{2}\right)$. The Midilli-Kucuk model could satisfactorily describe RH-convective drying of banana slices with $\mathrm{R}^{2}$, RMSE and $\chi^{2}$ in the ranges of $0.99947-0.99986,0.00002-0.00008$, and $0.0142-0.01618$ respectively. For energy consumption, RH condition increased the energy consumption such that at every $10 \%$ increase in $\mathrm{RH}$, a range of $17.9-41.0 \%$ increase in energy consumption was observed. In the case of thermal properties, endothermic peak revealed precise composition, fine particle size, and dispersion in a matrix of banana slices thus altering the transition in solid state. In effect, RH drying present new drying concept with prospecting thermodynamics absorbing properties. However, energy consumption issue needs to be addressed in further research.
\end{abstract}

Keywords: Endothermic reaction; crystallinity; moisture diffusivity; drying kinetics; sliced banana

Original scientific paper. Received 02 Sep 2020; revised 21 Jun 2021

\section{Introduction}

Drying technology is a complex thermal process due to unsteady heat and moisture transfer occurring simultaneously; a concept that researchers are still unravelling (Sahin \& Dincer, 2005). In order to understand the process, it is critical to model the control parameters to predict, design, and improve the results of the process. In the process of drying thin-layer samples, several mathematical models divided into theoretical, semi-theoretical and empirical models have been proposed. (Doymaz, 2011; Doymaz \& Kocayigit, 2012). The theoretical model considers the internal resistance to moisture transfer, while the empirical and semi theoretical models take into account the external resistance of moisture transfer between the air and product (Henderson \& Pabis, 1962; Ju et al., 2016). Fick's second law of diffusion continues to be the most widely used drying modelwhereasothermodelssuchasLogarithmic, Modified Page, Henderson-Pabis, Page, Midilli-Kucuk, Two terms and Newton are

Ghana Jnl Agric. Sci. 56 (2), 22 - 33

GJAS is an Open Access Journal and distributed under the terms of the Creative Commons (CC) License [CC BY 4.0] 
considered as empiricalmodels(Doymaz,2011). Mathematical model equations have been used to predict drying kinetics of whole banana (Da-Silva et al., 2014), banana slices (Joardder et al., 2014; Olawoye et al., 2017; Verma et al., 2014), banana cubes (Jiang et al., 2014) and banana paste and flour (Cabrera-Padilha et al., 2014; Rayo et al., 2015) using various drying conditions. However, there remains a gap in literature vis-à-vis the modeling of drying kinetics, thermal energy consumption and thermal properties of dried banana under different relative humidity $(\mathrm{RH})$ that needs to be bridged.

In banana preservation through drying, thermal properties are often altered, transformed and in some cases disperse completely the matrix of dried banana. From literature, the severity of drying impact on thermodynamics is dependent on the drying methods, drying procedures, nature of sample and drying conditions (Nunes et al., 2016).

This study was conducted in order to predict effectively the different $\mathrm{RH}$ of drying kinetics using mathematical model, and to assess the thermal energy consumption and thermal properties of banana under varied $\mathrm{RH}$ drying conditions.

\section{Materials and Methods}

\section{Preparation of Samples}

Ripped Bananas (Cavendish spp.) was obtained from a grocery market, Zhenjiang- China and transported to the School of Food Science and Biological Engineering laboratory in cartoon boxes. Samples were kept at room temperature until further used. After peeling, slices $(5 \mathrm{~mm}$ thick) were obtained using a cutter (SS-250, SEP Machinery Company Ltd, Guangzhou, China), before drying was performed. The initial moisture content (MC) was determined by the oven method (AOAC, 1990), on wet basis and was noted to be $76.05 \pm 0.8 \%$ (w.b).

Drying with Relative humidity ( $R H)$ convective control hot-air dryer

Drying was carried out with an advanced labscale hot-air convective dryer equipped with a humidity controlling device (range $0-99 \%$ ) as described previously (Sarpong et al., 2018).

\section{Experimental design for drying}

The sample $(60 \mathrm{~g})$ was loaded into a sieve loading tray into the dryer with aluminum foil cover after tarring to zero. Drying was carried out using a combination of four RH $(10,20$, 30 and $40 \%$ ) at $70^{\circ} \mathrm{C}$ with $\mathrm{m} / \mathrm{s}$ air velocity and continued until a constant weight was obtained. To ensure stable drying conditions, the drying system was run for $1 \mathrm{~h}$ before loading the sample. For the control (drying with no RH), the RH device was switched off to allow only the convective drying system (HAD) to dry banana at $70^{\circ} \mathrm{C}$ with $\mathrm{m} / \mathrm{s}$ air velocity and continued until a constant weight was obtained which ranged from $280-410$ min due to different drying conditions used.

\section{Modeling of drying kinetics}

According to Newton's heat transfer cooling law (Lewis, 1921), the moisture ratio (MR) of the sample is defined and expressed in Eq (1).

$$
M R=\frac{M-M_{e}}{M_{o}-M_{e}}=\exp (-k t) \ldots \ldots \ldots[1]
$$

Where $M_{e} M$, and $M_{o}$ and are the equilibrium moisture content of the initial moisture content and dry basis respectively at time $t$; $k$ is the drying constant. For the analysis of MR, the equilibrium moisture content was assumed to be zero (Man et al., 2014). At time (t), the drying rate (DR) of banana slices was calculated as follows:

$$
D R=\frac{M_{t 1}-M_{t 2}}{\mathrm{t}_{2}-t_{1}} \ldots \ldots \ldots \ldots \ldots[2]
$$


Where $t_{1}$ and $t_{2}$ are the drying times (min) at different times during drying; $M_{t 1}$ and $M_{t 2}$ are the moisture content of samples ( $g$ water per $g$ dry matter).

The 8 thin-layer drying model was fitted for the $(\mathrm{MR}, \mathrm{t})$ drying kinetics of banana slices, which are commonly used in scientific literature, as described in Table 1. Using MATLAB R2012
(MathWorks, USA) tool, regression analysis was performed. Three primary parameters such as coefficient determination $\left(\mathrm{R}^{2}\right)$, root mean square error (RMSE) and reduced chi-square $(\chi 2)$ were used to evaluate the adjustment/ goodness of fit to the models using Eq. (3-5). The best model was chosen based on highest and lowest $\chi 2$ and RMSE.

$$
\begin{aligned}
& \boldsymbol{R}^{2}=\frac{N \sum_{i=1}^{N} M R_{\text {pred }, i} M R_{\text {expt }, i}-\sum_{i=1}^{N} M R_{\text {pred }, i} \sum_{i=1}^{N} M R_{\text {expt } x, i}}{\sqrt{ }\left(N \sum_{i=1}^{N} M R_{\text {pred }, i}^{2}-\left(\sum_{i=1}^{N} M R_{p r e d, i}\right)^{2}\right)\left(N \sum_{i=1}^{N} M R_{\text {expt }, i}^{2}-\left(\sum_{i=1}^{N} M R_{\text {expt }, i}\right)^{2}\right)} \ldots \ldots \ldots[3]
\end{aligned}
$$

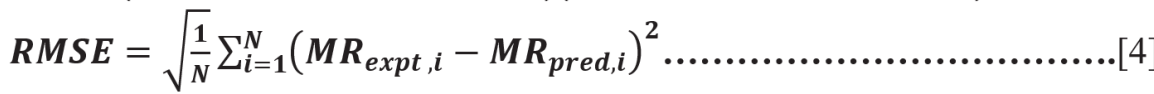

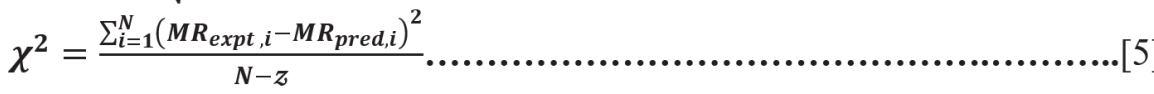

Where $M R_{\text {expt, } i}$ and $M R_{\text {pred }, i}$ are the experimental and predicted dimensionless $M R$ respectively, $N$ is the number of observations, and $z$ is the number of constants. The best model to describe the drying kinetics of banana slices under $\mathrm{RH}$ conditions was chosen as the one with the highest $R^{2}$ and least $R M S E$ and $X^{2}$ (Doymaz, 2011; Wu et al., 2014).

\section{Effective moisture diffusivity calculation}

Based on Fick's second law (law of diffusion), the theoretical model in thin-layer for most agricultural products is expressed in Eq 6.

$$
\frac{\partial M}{\partial t}=D_{e f f} \nabla^{2} M
$$

Where Deff is effective moisture diffusivity $\left(\mathrm{m}^{2} / \mathrm{s}\right), \frac{\partial M}{\partial t}$ is the rate of change, $\nabla$ is concentration $\left(\mathrm{mol} / \mathrm{m}^{3}\right), \mathrm{M}$ is the length $(\mathrm{m})$.

For slab geometry calculations, the diffusion coefficient, $\left(\mathrm{m}^{2} / \mathrm{s}\right)$ can be expressed based on the following assumptions (constant diffusion coefficient, single-dimensional moisture movement, volume change, consistent temperature, and negligible external resistance) (Crank, 1979)

$$
M R=\frac{M-M_{e}}{M_{O}-M_{e}}=\frac{8}{\pi^{2}} \sum_{n=1}^{\infty} \frac{1}{(2 n-1)^{2}} \exp \left[-\frac{(2 n-1)^{2} \pi^{2} D_{e f f} t}{4 L^{2}}\right] \ldots \ldots \ldots \ldots[7]
$$

Where $M, M o$ and $M e$ are the average, initial and equilibrium moisture contents (g/g d.b) of the sample respectively at time $t, D_{\text {eff }}$ is the constant effective diffusivity $\left(\mathrm{m}^{2} / \mathrm{s}\right) . L$ and $t$ represent half the thickness of the banana slice and the drying time (s) respectively. Only the first term of the Eq.(7) can be used for long drying times (Xiao et al., 2012)
$M R=\frac{M-M_{e}}{M_{o}-M_{e}}=\frac{8}{\pi^{2}} \exp \left(-\frac{\pi^{2} D_{\text {eff }} t}{4 L^{2}}\right)$

The slope $\left(k_{0}\right)$ is calculated by plotting $\ln (M R)$ against time

$$
k_{0}=\frac{\pi^{2} D_{e f f}}{4 L^{2}}
$$




\section{Energy consumption}

The total energy consumption for drying banana under different $\mathrm{RH}$ conditions was measured using an electric energy meter with $0.01 \mathrm{kWh}$ accuracy while the specific energy consumption (the energy required to dry 1 $\mathrm{kg}$ of banana) was calculated by Eq. (3.10) (Jiang et al., 2017)

$E_{s}=\frac{E_{t}}{W_{w}} x 1000 \ldots \ldots \ldots \ldots[10]$

Where $E_{s}$ is the specific energy consumption, $E_{t}$ is the total energy consumption, and $W_{w}$ is the initial weight of banana.

\section{Differential scanning calorimetry (DSC)}

The thermal behavior of the samples was studied by using a $\mu \mathrm{DSC} 7$ (Setaram, Caluire, France) furnished with a cooling bath (JULABO, Labortechnik GmbH, 77960 Seelbach, Germany) and adjusted with Naphthalene. Nitrogen was used to prevent water condensation at low temperatures, during the experiment. To obtain the spectra, samples (2 $\mathrm{mg}$ ) were placed on $\mu \mathrm{DSC}$ cell, sealed with a crimper and placed in the scanning calorimetry device. The spectra (data) were obtained using Data Acquisition (version 4.1D-TA Instruments) and Calisto Processing (version 1.065-Setaram, Caluire, France) software. The DSC was taken at the temperature range $20-120^{\circ} \mathrm{C}$ and scanned at $1.2^{\circ} \mathrm{C} \mathrm{min}^{-1}$ and isotherms time were set at 15 and $10 \mathrm{~min}$ for initial and the final temperatures respectively.

\section{Statistical analysis}

Data were processed and presented as Means \pm SD using OriginPro 9.2 (Origin Lab Corporation, Northampton, MA, USA). Further comparisons were done with one-way ANOVA, Pearson's coefficient of correlation and turkey test using XLSTAT (Addinsoft Inc USA) respectively.

\section{Results and Discussion}

Effect of Relative Humidity on Drying Curves

The moisture content of sliced banana samples was reduced until constant moisture content was obtained from the initial moisture content of $76.05 \%$. Moisture ratio (MR) decreased exponentially with drying time for all $\mathrm{RH}$ samples. The results of the kinetic curves of drying banana slices at $75^{\circ} \mathrm{C}$ under different relative humidity $(10,20,30$ and $40 \%)$ are shown in Fig. 1a. The longest drying time of $410 \mathrm{~min}$ was obtained at $40 \% \mathrm{RH}$ to achieve constant moisture content under $70^{\circ} \mathrm{C}$ drying condition whilst HAD observed the shortest drying time (280 $\mathrm{min})$ as a result of dried atmospheric condition in the drying chamber for convective drying system. However, $10 \%, 20 \%$ and $30 \%$ RH achieved this constant moisture content in 290, 320 and $390 \mathrm{~min}$ which are equivalents to $29.3,21.0$ and $4.8 \%$ drying time reduction respectively when compared with $40 \% \mathrm{RH}$. These results were similar to the observation made by $\mathrm{Ju}$ et al. (2016) who concluded that lower relative humidity $(\mathrm{RH})$ predicts a lower moisture content than higher RH. This phenomenon is caused by a rapid increase in the internal temperature of the product (Fig. 1c) of the sample under $10 \% \mathrm{RH}$ condition which reached a maximum temperature of $73.5 \pm 1.5^{\circ} \mathrm{C}$ compared with $70.4 \pm 1.4,68.5 \pm$ 1.8 and $70.1 \pm 2.80^{\circ} \mathrm{C}$ for 20,30 and $40 \% \mathrm{RH}$ respectively. This high internal temperature of banana slice at $10 \% \mathrm{RH}$ provided an additional driving force for water diffusion and promoted the internal moisture movement toward achieving highest moisture reduction and drying rate (Fig 1c).

Drying rates (DR), after $30 \mathrm{~min}$ was in the range of $0.0056-0.0069 \mathrm{~kg} / \mathrm{kg}$ for RH samples whilst HAD observed $0.00733 \mathrm{~kg} / \mathrm{kg}$ as depicted in Fig. 1b. DR peaked at $120 \mathrm{~min}$ for all the drying conditions with higher value of $0.0172 \mathrm{~kg} / \mathrm{kg}$ for $10 \% \mathrm{RH}$ whilst 20,30 
and $40 \% \mathrm{RH}$ recorded $0.015,0.0125$ and $0.0092 \mathrm{~kg} / \mathrm{kg}$ respectively. Meanwhile, the highest DR $(0.01873 \mathrm{~kg} / \mathrm{kg})$ was observed in HAD conditions affirming the highest moisture loss in the drying of banana sample. There was no constant period, and most of the drying occurred during the rate of decline. This effect was related to the availability of a large amount of free moisture which was removed during the initial stages of drying (Doymaz, 2014; Mghazli et al., 2017). The falling period was governed by water diffusion in banana sample; a typical behavior observed for other fruits (Lee et al., 2010; Mghazli et al., 2017; Sarker et al., 2013). The slow pace of the falling period is a result of the evaporation of moisture from the surface of banana slices at the initial stages due to a higher heat transfer and mass transfer coefficient. Moreover, Sarker et al. (2013) suggested that the gel that is formed as a result of protein denaturing impeded water movement inside the banana matrix to the surface for evaporation, thus slowing the dehydration process.

\section{Fitting of the Drying Curves}

For the various RH drying conditions of each run, the experimental data fitted to eight models (Table 1) and $\mathrm{R}^{2}, \chi^{2}$ and RMSE were used to evaluate the performance of each model. The obtained model constant parameters for the eight models are summarized in Table 2. All the models gave consistently $\mathrm{R}^{2}$ values in the range of 0.97007-0.99983; indicating that all the models could be used to describe the drying behavior of banana slices under $10-40 \% \mathrm{RH}$ conditions. However, Midilli-Kucuk displayed the highest average value of $\mathrm{R}^{2}$, lowest $\chi^{2}$ and RMSE (Table 2). The changes in the $\mathrm{R}^{2}, \chi^{2}$ and RMSE range between 0.99947-0.99986, $0.00002-0.00008$, and 0.0142-0.01618 respectively. Consequently, Midilli-Kucuk model is the best among the tested models that accurately expressed the thin-layer drying behavior of banana slices under the studied drying conditions.

Good conformity is observed between the experimental and predicted moisture ratio shown in Fig. 1d under 10-40\% RH conditions for Midilli-Kucuk model. Similarly, MidilliKucuk model was used to effectively predict drying kinetics of Moroccan rosemary leaves (Mghazli et al. 2017), thyme (Doymaz, 2011) spinach (Karaaslan \& Tunçer, 2008) and rough rice (Hacıhafizoğlu et al., 2008).

\section{Determination of Effective Moisture Diffusivity $\left(D_{e f f}\right)$}

Isothermal temperature at $75^{\circ} \mathrm{C}$ was maintained during all the RH drying processes. $D_{\text {eff }}$ values were within the range of $1.805 \times 10^{-8}-1.956$ $\times 10^{-8} \mathrm{~m}^{2} / \mathrm{s}$ (Table 2) indicating that moisture movement in the banana slice was in the liquid form (Saravacos \& Kostaropoulos, 2002). $D_{\text {eff }}$ decreased with increase in RH except for $20 \%$ RH which recorded the highest $D_{\text {eff }}$ value. Sample internal temperature (Table 2) revealed that $20 \% \mathrm{RH}$ recorded highest temperature even though Isothermal temperature $\left(75^{\circ} \mathrm{C}\right)$ was used for all RH. So RH with highest sample internal temperature recorded highest $D_{\text {eff }}$ value. This was confirmed by other authors who used different drying temperatures in determining $D_{\text {eff }}$ value (Doymaz, 2011; Hacıhafizoğlu et al., 2008; Mghazli et al., 2017).

\section{Energy consumption}

Fig. 2 shows the energy consumption and specific energy consumption in $\mathrm{RH}$ convection drying of banana under varied RH conditions. The energy consumption needed to obtain a constant dry weight of banana ranged from 10.21-17.08 kWh. Similarly, $8-12 \mathrm{kWh}$ energy consumption was observed in convection drying of pomegranate arils at 
$70^{\circ} \mathrm{C}$ at varied air velocity (Motevali et al., 2011). In their research, air velocity, temperature and drying time impacted energy consumption significantly $(\mathrm{p}<0.05)$. Zhao et al. (2018) also observed that different thicknesses of sample could play a role in energy consumption of the drying system. Observably, RH and drying time played a significant $(p<0.05)$ role in the energy consumption of drying banana with a direct relation. In effect, the RH condition increased the energy consumption such that at every $10 \%$ increase in $\mathrm{RH}$, a range of 17.9$41.0 \%$ increase in energy consumption was observed. In similar manner, specific energy consumption increased with increasing $\mathrm{RH}$ which corresponded with an increase in drying time. In the case of $40 \% \mathrm{RH}$, maximal value of $284.72 \mathrm{kWh} / \mathrm{kg}$ was observed whilst 201.39 $\mathrm{kWh} / \mathrm{kg}$ was observed in $10 \% \mathrm{RH}$. However, HAD drying condition recorded the minimal specific energy consumption of $170.13 \mathrm{kWh} /$ $\mathrm{kg}$ with a significant difference $(\mathrm{p}<0.05)$ when compared with all four RH drying conditions.

\section{Effect of RH on characteristics of DSC thermogram}

Thermal properties of the banana slices were examined through a DSC thermogram as shown in Fig. 3. In this concept, DSC measured heat absorbed or released during the transition state of the sample when subjected to measurable heat range (in this case, $20-120^{\circ} \mathrm{C}$ ). From Fig. 3, the first endothermic peak for the four $\mathrm{RH}$ and $\mathrm{HAD}$ conditions ranged from $30-35^{\circ} \mathrm{C}$ and the variation was caused by precise composition, particle size, and dispersion in a matrix of banana slices (Izidoro et al., 2011) as a result of varied RH drying condition. When anhydrous, the banana slices showed endothermic reaction and again samples exhibited varied peaks (Tp).
For $\mathrm{HAD}, 10 \%$ and $20 \% \mathrm{RH}$, Tp were $85^{\circ} \mathrm{C}$ while $79^{\circ} \mathrm{C}$ and $90^{\circ} \mathrm{C}$ were observed for $30 \%$ and $40 \% \mathrm{RH}$ respectively. The intensity of the endothermic phenomenon also revealed the transition in solid state of the sample and from Fig. 3, was very pronounced in lower RH. This is an indication of high degree of crystallinity, thus, making the sample more brittle. Also, other texture profile properties such as stiffness, hardness, tensile and melting point were highly related to the crystallinity of the sample. The $10 \% \mathrm{RH}$ and HAD did not exhibit another endothermic peak. However, a third peak was observed in $20 \%, 30 \%$ and $40 \% \mathrm{RH}$ at $105^{\circ} \mathrm{C}$, $110^{\circ} \mathrm{C}$ and $120^{\circ} \mathrm{C}$ which is ascribed to the caramelization (Izidoro et al., 2011).

\section{Conclusion}

The drying kinetics, energy consumption and thermal properties of banana slices were investigated under four RH and HAD (used as control) conditions at a temperature of $75^{\circ} \mathrm{C}$. A significant reduction in $\mathrm{MC}$ was observed in lesser $\mathrm{RH}$ as a result of increased rise in sample internal temperature. Among the eight thin-layer drying models studied, the Midilli-Kucuk model was judged the best model from its R2, $\chi^{2}$ and RMSE values. The model constant and drying time for various model regressions for MR calculations was determined and reported. $\mathrm{RH}$ increased the energy and specific energy consumption of drying banana with a direct relation. The DSC thermogram revealed that the $\mathrm{RH}$ affected the precise composition, particle size, and dispersion in a matrix of dried banana such that the transition in solid state was also altered. Again, lower RH increased the crystallinity of banana, thus, making the sample more brittle when compared with higher RH. 


\section{REFERENCES}

Akoy, E. (2014) Experimental characterization and modeling of thin-layer drying of mango slices. International Food Research Journal 21 (5), $1911-1917$.

Akpinar, E., Midilli, A. \& Bicer, Y. (2003) Single layer drying behaviour of potato slices in a convective cyclone dryer and mathematical modeling. Energy conversion and management 44 (10), 1689 - 1705.

AOAC. (1990) Official method of analysis. Association of Official Analytical Chemists Arlington, VA.

Cabrera-Padilha, R. Y., Oladeinde, T. O., Finzer, J. R. D. \& Limaverde, J. R. (2014) Drying of banana paste in rotatory dryer with inert bed. Brazilian Journal of Food Technology 17 (1), $41-50$.

Chavan, B. R., Yakupitiyage, A. \& Kumar, S. (2008) Mathematical Modeling of Drying Characteristics of Indian Mackerel (Rastrilliger kangurta) in Solar-Biomass Hybrid Cabinet Dryer. Drying Technology 26 (12), 1552 1562. DOI: $10.1080 / 07373930802466872$

Crank, J. (1979) The mathematics of diffusion: Oxford university press.

Da Silva, W. P., E Silva, C. M. D. P. S., Gama, F. J. A. \& Gomes, J. P. (2014) Mathematical models to describe thin-layer drying and to determine drying rate of whole bananas. Journal of the Saudi Society of Agricultural Sciences 13 (1), $67-74$.

De La Fuente-Blanco, S., De Sarabia, E. R.-F., Acosta-Aparicio, V., Blanco-Blanco, A. \& GallegoJuárez, J. (2006) Food drying process by power ultrasound. Ultrasonics $\mathbf{4 4}$, e523-e527.

Doymaz, I. (2011) Drying of thyme (Thymus Vulgaris L.) and selection of a suitable thin-layer drying model. Journal of Food Processing and Preservation 35 (4), $458-465$.

Doymaz, I. (2014) Infrared drying of button mushroom slices. Food Science and Biotechnology 23 (3), $723-729$.
Doymaz, I. \& Kocayigit, F. (2012) Effect of pretreatments on drying, rehydration, and color characteristics of red pepper ('Charliston' variety). Food Science and Biotechnology 21 (4), $1013-1022$.

Hacıhafizoğlu, O., Cihan, A. \& Kahveci, K. (2008) Mathematical modelling of drying of thin layer rough rice. Food and Bioproducts Processing 86 (4), $268-275$.

DOI: http://dx.doi.org/10.1016/j.fbp.2008.01.002.

Henderson, S. M. (1974) Progress in developing the thin layer drying equation. Transactions of the ASAE 17, 1167 - 1178.

Jiang, H., Zhang, M., Mujumdar, A. S. \& Lim, R.X. (2014) Comparison of drying characteristic and uniformity of banana cubes dried by pulsespouted microwave vacuum drying, freeze drying and microwave freeze drying. Journal of the Science of Food and Agriculture 94 (9), $1827-1834$.

Jiang, N., Liu, C., Li, D., Zhang, Z., Liu, C., Wang, D., Niu, L. \& Zhang, M. (2017) Evaluation of freeze drying combined with microwave vacuum drying for functional okra snacks: Antioxidant properties, sensory quality, and energy consumption. LWT - Food Science and Technology 82, $216-226$.

Joardder, M. U., Karim, A., Kumar, C. \& Brown, R. J. (2014) Determination of effective moisture diffusivity of banana using thermogravimetric analysis. Procedia Engineering 90, 538 - 543.

Ju, H.-Y., Zhang, Q., Mujumdar, A., Fang, X.-M., Xiao, H.-W. \& Gao, Z.-J. (2016) Hot-air Drying Kinetics of Yam Slices under Step Change in Relative Humidity. International Journal of Food Engineering 12 (8), 783 792.

Karaaslan, S. N., \& Tunçer, I. K. (2008) Development of a drying model for combined microwave-fan-assisted convection drying of spinach. Biosystems Engineering 100 (1), 44 - 52. DOI: http://dx.doi.org/10.1016/j. biosystemseng.2007.12.012. 
La Fuente, C. I. A., Zabalaga, R. F. \& Tadini, C. C. (2017) Combined effects of ultrasound and pulsed vacuum on air-drying to obtain unripe banana flour. Innovative Food Science \& Emerging Technologies 44, 123 - 130.

Lee, S.-H., Ko, S.-C., Kang, S.-M., Cha, S. H., Ahn, G.-N., Um, B.-H. \& Jeon, Y.-J. (2010) Antioxidative effect of Ecklonia cava dried by far infrared radiation drying. Food Science and Biotechnology 19 (1), 129 - 135.

Lewis, W. K. (1921) The Rate of Drying of Solid Materials. Journal of Industrial Engineering Chemistry, 13 (5), 427 - 432.

Man, L. V., Orikasa, T., Koide, S., Muramatsu, Y. \& Tagawa, A. (2014) Effect of Different Drying Methods on Physical and Chemical Attributes of Blanched Green Bell Pepper. Food Science and Technology Research 20 (4), 775 - 783.

Mghazli, S., Ouhammou, M., Hidar, N., Lahnine, L., Idlimam, A. \& Mahrouz, M. (2017) Drying characteristics and kinetics solar drying of Moroccan rosemary leaves. Renewable Energy 108, 303 - 310. DOI: http://dx.doi. org/10.1016/j.renene.2017.02.022.

Midilli, A., Kucuk, H., \& Yapar, Z. (2002) A NEW MODEL FOR SINGLE-LAYER DRYING. Drying Technology 20 (7), 1503 - 1513. DOI: 10.1081/DRT-120005864.

Motevali, A., Minaei, S. \& Khoshtagaza, M. H. (2011) Evaluation of energy consumption in different drying methods. Energy Conversion and Management 52 (2), 1192 - 1199.

Nunes, J. C., Lago, M. G., Castelo-Branco, V. N., Oliveira, F. R., Torres, A. G., Perrone, D. and Monteiro, M. (2016) Effect of drying method on volatile compounds, phenolic profile and antioxidant capacity of guava powders. Food Chemistry 197, $881-890$.

O'Callaghan, J. R., Menzies, D. J., \& Bailey, P. H. (1971) Digital simulation of agricultural drier performance. Journal of Agricultural Engineering Research 16 (3), 223 - 244. DOI: http://dx.doi.org/10.1016/S00218634(71)80016-1.
Olawoye, B. T., Kadiri, O. \& Babalola, T. R. (2017) Modelling of thin-layer drying characteristic of unripe Cardaba banana (Musa ABB) slices. Cogent Food \& Agriculture 3 (1), 1290013. http://dx.doi.org/10.1080/23311932.2017.129 0013

Omolola, A. O., Jideani, A. I. \& Kapila, P. F. (2014) Modeling microwave drying kinetics and moisture diffusivity of Mabonde banana variety. International Journal of Agricultural and Biological Engineering 7 (6), p. 107.

Rayo, L. M., Chaguri E Carvalho, L., Sardá, F. a. H., Dacanal, G. C., Menezes, E. W. \& Tadini, C. C. (2015) Production of instant green banana flour (Musa cavendischii, var. Nanicão) by a pulsed-fluidized bed agglomeration. LWT Food Science and Technology 63 (1), 461 469.

Sacilik, K. (2007) Effect of drying methods on thinlayer drying characteristics of hull-less seed pumpkin (Cucurbita pepo L.). Journal of Food Engineering 79 (1), 23 - 30.

Sahin, A. \& Dincer, I. (2005) Prediction of drying times for irregular shaped multi-dimensional moist solids. Journal of Food Engineering 71 (1), $119-126$.

Saravacos, G. D., \& Kostaropoulos, A. E. (2002) Handbook of food processing equipment: Springer Science \& Business Media.

Sarker, M. S. H., Ibrahim, M. N., Aziz, N. A., \& Punan, M. S. (2013) Drying Kinetics, Energy Consumption, and Quality of Paddy (MAR219) during Drying by the Industrial Inclined Bed Dryer with or without the Fluidized Bed Dryer. Drying Technology 31 (3), 286 - 294. DOI: $10.1080 / 07373937.2012 .728270$.

Sarpong, F., Yu, X., Zhou, C., Hongpeng, Y., Uzoejinwa, B. B., Bai, J. \& Ma, H. (2018) Influence of anti-browning agent pretreatment on drying kinetics, enzymes inactivation and other qualities of dried banana (Musa ssp.) under relative humidity-convective air dryer. Journal of Food Measurement and 
Characterization 12 (2), 1229 - 1241. DOI: 10.1007/s11694-018-9737-0.

Vega, A., Uribe, E., Lemus, R., \& Miranda, M. (2007) Hot-air drying characteristics of Aloe vera (Aloe barbadensis Miller) and influence of temperature on kinetic parameters. LWTFood Science and Technology 40 (10), 1698 $-1707$.

Verma, D., Kaushik, N. \& Rao, P. S. (2014) Application of high hydrostatic pressure as a pretreatment for osmotic dehydration of banana slices (Musa cavendishii) finishdried by dehumidified air drying. Food and bioprocess technology 7 (5), 1281 - 1297.

Wu, B., Ma, H., Qu, W., Wang, B., Zhang, X., Wang, P., Pan, Z. (2014) Catalytic infrared and hot air dehydration of carrot slices. Journal of Food Process Engineering, 37 (2), 111 - 121.
Xiao, H. W., Yao, X. D., Lin, H., Yang, W. X., Meng, J. S., \& Gao, Z. J. (2012) Effect of SSB (superheated steam blanching) time and drying temperature on hot air impingement drying kinetics and quality attributes of yam slices. Journal of Food Process Engineering, 35 (3), $370-390$.

Zhao, F., Han, F., Zhang, S., Tian, H., Yang, Y. \& Sun, K. (2018) Vacuum drying kinetics and energy consumption analysis of $\mathrm{LiFePO} 4$ battery powder. Energy 162, $669-681$.

Zidoro, D. R., Sierakowski, M.-R., Haminiuk, C. W. I., De Souza, C. F. \& Scheer, A. D. P. (2011). Physical and chemical properties of ultrasonically, spray-dried green banana (Musa cavendish) starch. Journal of Food Engineering 104 (4), 639 - 648.

TABLE 1

Mathematical models applied to the simulation of banana slices drying under various $R H$

\begin{tabular}{lll}
\hline Model name & Model & Reference \\
\hline Lewis & $M R=\exp (-k t)$ & O'Callaghan, Menzies, and Bailey (1971) \\
Page & $M R=\exp \left(-k t^{n}\right)$ & Akoy (2014) \\
Modified page & $M R=\left[\exp \left(-k t^{n}\right)\right]$ & Vega, Uribe, Lemus, and Miranda (2007) \\
Wang and Singh & $M R=1=a t+b t^{2}$ & Omolola, Jideani, and Kapila (2014) \\
Midilli-Kucuk & $M R=a \exp \left(-k t^{n}\right)+b t$ & Midilli, Kucuk, and Yapar (2002) \\
Two term & $M R=a \cdot \exp \left(-k_{0} t\right)+b \cdot \exp \left(-k_{l} t\right)$ & Sacilik (2007) \\
Verma et al. & $M R=a \cdot \exp (-k t)+(1-a) \exp (-g t)$ & Akpinar, Midilli, and Bicer (2003) \\
Henderson and Pabis & $M R=a \cdot \exp (-k t)$ & Henderson (1974) \\
\hline
\end{tabular}


TABLE 2

Curve fitting criteria for 8 mathematical models and parameters at $75^{\circ} \mathrm{C}$ and $10-40 \%$ RH drying conditions

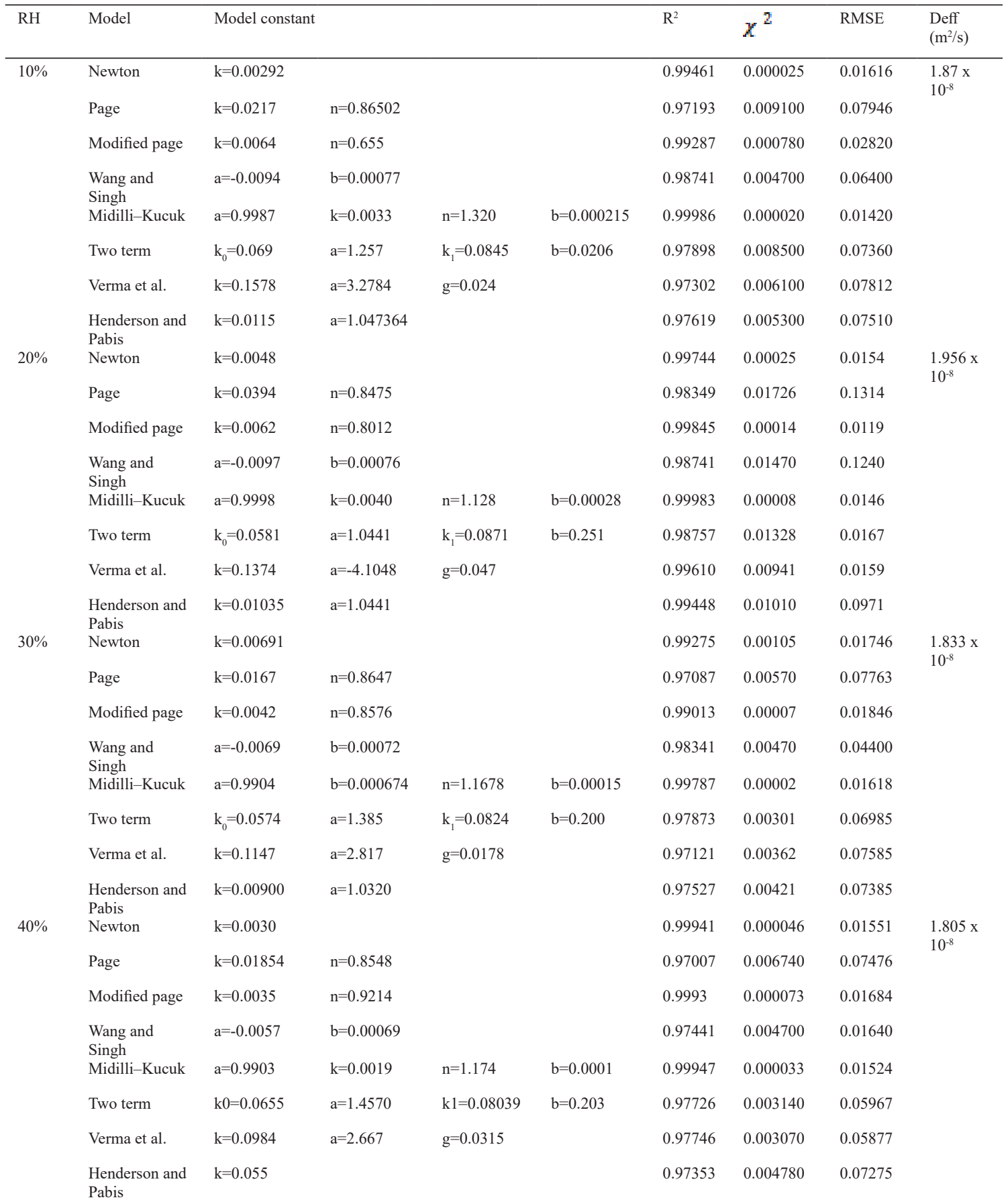




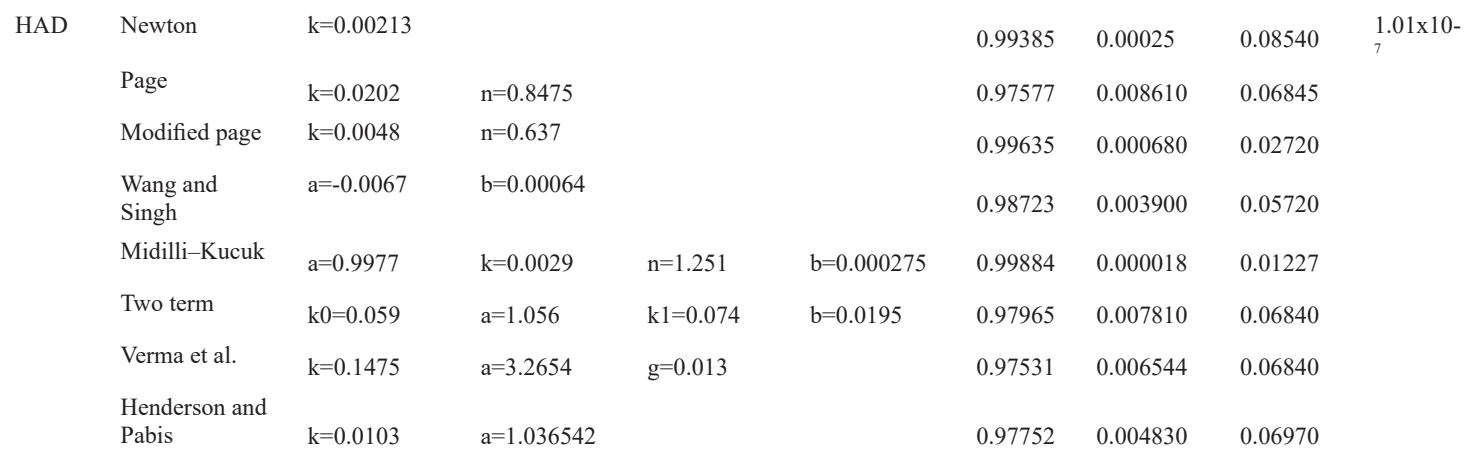
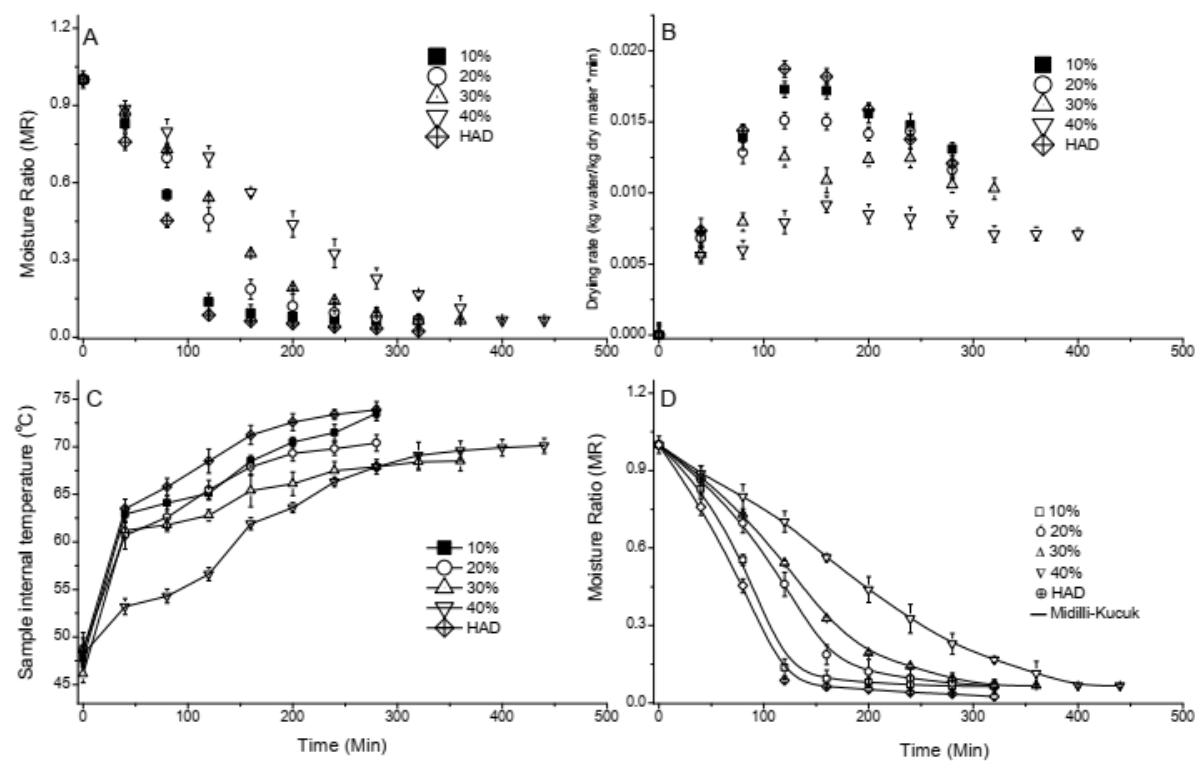

Fig. 1: Drying Kinetics of banana slices dried at $70^{\circ} \mathrm{C}$ temperature and $2.0 \mathrm{~m} / \mathrm{s}$ air velocity under varied Relative Humidity. (a) Variation of Moisture ratio versus drying time (b) Variation of drying rate versus drying time (c) The internal temperature and (d). Experimental and simulated curves using Midilli-Kucuk model. 


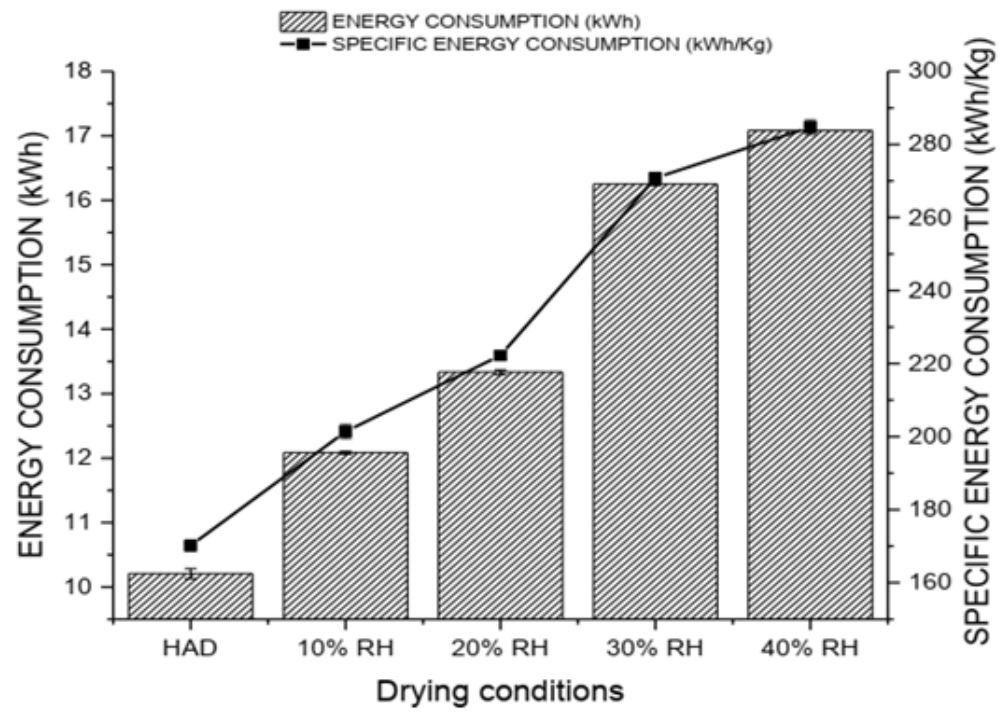

Fig. 2: Energy consumption and specific energy consumption in RH-convection drying of banana under varied RH conditions.
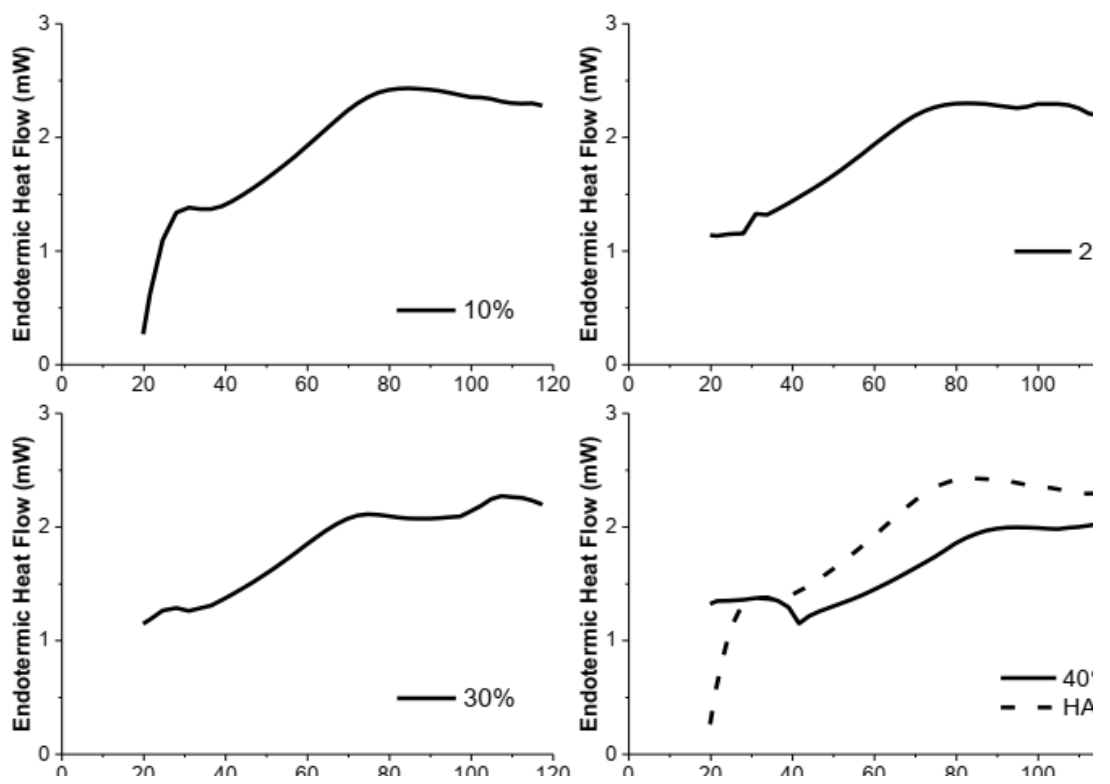

Fig. 3: DSC thermograms of banana slices dried by a varied RH drying system. 